\title{
Endo and Exoskeleton: New Technologies on Composite Materials
}

\author{
Luca Fiorillo 1,*(D), Cesare D'Amico ${ }^{1}$, Anna Yurjevna Turkina ${ }^{2}$, Fabiana Nicita ${ }^{1}$, \\ Giulia Amoroso ${ }^{1}$ and Giacomo Risitano ${ }^{3}$ (D) \\ 1 Department of Biomedical and Dental Sciences and Morphological and Functional Imaging, \\ Messina University, 98122 Messina, ME, Italy; cdamico@unime.it (C.D.); fabin92@hotmail.it (F.N.); \\ giulia.amoroso@hotmail.it (G.A.) \\ 2 Institute of Dentistry, Department of Therapeutic dentistry, \\ I.M. Sechenov First Moscow State Medical University, 119146 Moscow, Russia; anna@turkin.su \\ 3 Department of Engineering, Messina University, 98122 Messina, ME, Italy; grisitano@unime.it \\ * Correspondence: 1fiorillo@unime.it
}

Received: 10 December 2019; Accepted: 30 December 2019; Published: 2 January 2020

check for updates

\begin{abstract}
The developments in the field of rehabilitation are proceeding hand in hand with those of cybernetics, with the result of obtaining increasingly performing prostheses and rehabilitations for patients. The purpose of this work is to make a brief exposition of new technologies regarding composites materials that are used in the prosthetic and rehabilitative fields. Data collection took place on scientific databases, limited to a collection of data for the last five years, in order to present news on the innovative and actual materials. The results show that some of the most commonly used last materials are glass fibers and carbon fibers. Even in the robotics field, materials of this type are beginning to be used, thanks above all to the mechanical performances they offer. Surely these new materials, which offer characteristics similar to those in humans, could favor both the rehabilitation times of our patients, and also a better quality of life.
\end{abstract}

Keywords: biomechanical phenomena; elasticity; bioengineering; fiberglass; carbon fiber; prosthesis; rehabilitation research

\section{Introduction}

\subsection{Background}

In recent years new technologies in bioengineering and industrial fields have enabled the creation of new materials. These materials suitable for the rehabilitation of patients in the different districts of the body offer excellent integration capabilities and excellent biomechanical characteristics. Some of these materials also show biocompatibility characteristics, which makes them perfect to stay in contact with the body's tissues [1]. Composite materials are the materials on which the study will focus. In material science, a composite material is a heterogeneous material, that is, made up of two or more phases with different physical properties, whose properties are better than those of the phases that constitute it. Usually, the different phases in the composite are made of different materials, as in the case of carbon fiber and epoxy resin composites. However, there are exceptions where the different phases are made of the same material, such as $\mathrm{SiC} / \mathrm{SiC}(\mathrm{SiC}-\mathrm{SiC})$ matrix composite is a particular type of ceramic matrix composite) and self-reinforced polypropylene (SRPP) [2]. Composite materials could be both artificial or natural. Some examples of naturally occurring composite materials are wood, in which cellulose fibers are dispersed in a phase of lignin, and bones, in which collagen is reinforced by mineral apatite. 
Glass fibers are used for the production of composite materials or advanced structural materials in which different components are integrated together to produce a material with superior characteristics from a physical, mechanical, chemical, aesthetic point of view. In the science and technology of materials, on the other hand, carbon fiber is a material having a thin, thread-like structure made of carbon, generally used in the production of a great variety of "composite materials", so called because they consist of two or more materials, which in this case are carbon fibers and a so-called matrix, generally of resin (or plastic or metal) whose function is to hold the resistant fibers in place (so as to maintain the correct orientation in absorbing the efforts), to protect the fibers and also to maintain the shape of the composite manufactured article. A separate discussion should be made regarding ceramic composite materials. Moreover, a different topic is all the biomaterials originating from living matter, such as bone substitutes. Thanks to new technologies, these materials, just like those under examination of the communication, could be milled or printed with CAD (Computer Aided Design) CAM (Computer Aided Manufacturing) systems [3-7]. In the technopolymers field, the composite flow molding (CFM) technology allows the production of composite materials strongly reinforced with long fiber without damaging the fibers. The reinforcement content also reaches $62 \%$ by volume to ensure maximum strength. With this process various combinations of reinforcements (carbon, glass, and Kevlar fibers) and thermoplastic resins (polyether ether ketone (PEEK), polyetherimide (PEI), polyphenylene sulfide (PPS)) are possible; the products thus obtained allow the industry to meet the growing demand for lightweight materials with excellent mechanical, chemical and thermal properties [8,9]. Form memory polymers, although already present on the market with different types of products, new materials and their development continues today to be able to identify characteristics, shapes and other possible applications. In fact their particular properties, unique in the world of plastics, mean that the still possible uses are infinite, ranging from commonly used products, made with standard industrial techniques, to functional elements of 'intelligent' junction, to pieces with good ergonomics or simply tools to improve the performance or comfort of the product in which they are inserted. In the way of "intelligent materials" there are also some membranes based on shape memory polymers. They exploit the principle of thermal vibration, that is, when the room temperature is below the activation point (dictated by the body temperature), the molecular structure stiffens, lowering the permeability, thus allowing to maintain the body temperature; when the room temperature exceeds the activation point, the molecular structure softens creating free spaces between the molecules, allowing the elimination of water vapor and excess body heat $[10,11]$. These membranes could be used to make water-proof and wind-resistant fabrics, which are breathable and at the same time permeable to water vapor, thus guaranteeing the anti-condensation characteristic. In the dental field, for the production of removable or fixed, implant prosthetics and orthodontic devices, the use of resins based on methacrylate (poly(methyl methacrylate (PMMA)) and composites (bisphenol A-glycidyl methacrylate (biS-GMA)) is widespread [12]. In this manuscript, different issues related to these two technologies have been evaluated. As far as PMMA is concerned, the limits of these materials are: the imperfect repeatability of the polymerization process, limited processing times, poor biocompatibility, which could lead to the onset of considerable safety problems for the health of operators during the phases of processing of prosthetic devices, as well as of patients during the completion phases in the oral cavity and in the subsequent daily use. As for biS-GMA, the limits concern above all their operating procedures, which are quite complicated and require long transformation times; it could be associated with the high cost of the materials themselves, moreover, there are difficulties in mechanically making surfaces that are perfectly shiny and compact. This causes quite significant plaque engraftment in the oral cavity, affecting the biocompatibility of the finished devices. As for fiberglass, on the other hand, common experience shows that monolithic glass is a fragile material. If it is instead spun at diameters of less than a tenth of a millimeter it loses its characteristic fragility to become a material with high mechanical strength and resilience [12]. 


\subsection{Aim}

The aim of this manuscript is to investigate about modern and innovative prosthetic and rehabilitative materials.

\section{Results}

\subsection{Search}

The results obtained from a recent (last five years) literature search concerning innovative biomedical materials provide detailed information regarding the physical, chemical and biocompatibility characteristics of these materials; but also, their applications. Used search terms were: ("glass fiber" (All Fields) OR "carbon fiber" (All Fields) OR "composite materials" (All Fields)) AND ("Biomed J Sci Tech Res" (Journal) OR "biomedical" (All Fields)) OR ("prostheses and implants" (MeSH Terms) OR ("prostheses" (All Fields) AND "implants" (All Fields)) OR "prostheses and implants" (All Fields) OR "prosthesis" (All Fields)) OR ("rehabilitation" (MeSH Terms) OR "rehabilitation" (All Fields) OR "rehabilitative" (All Fields)).

\subsection{Glass Fiber}

The fragility of the common glass is due to the large number of crystallization defects that act as microfractures and stress concentration zones. On the contrary, glass fiber does not present all these defects, therefore it reaches mechanical strengths close to the theoretical resistance of the covalent bond. Different types of fibers could be distinguished according to their characteristics, which condition their use. Glass fibers are widely used in the production of structural composites in the aerospace, nautical and automotive fields, associated with different matrices, for example polyamide or epoxy, still synthetic resins [13-15]. Glass fiber is largely used in dental field, for single, multi teeth restauration (Figure 1).

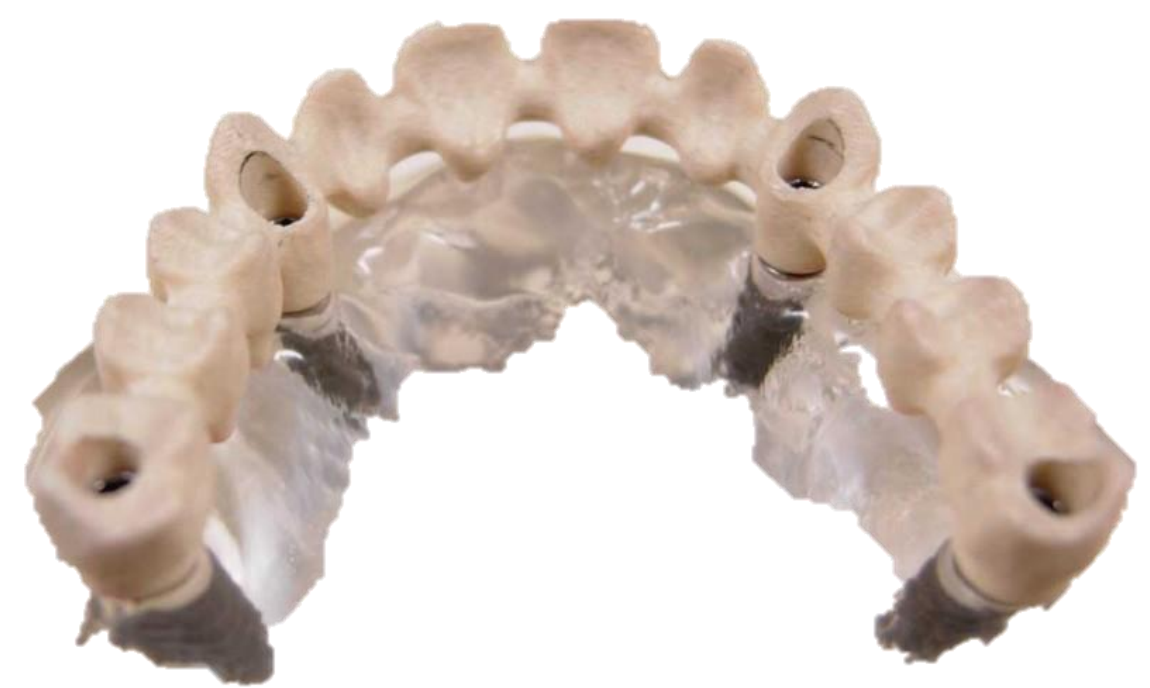

Figure 1. Glass fiber full arch implant supported dental structure. By emmekappadental.it accessed on 6 July 2019.

They are not usually used in the production of composites with metallic or ceramic matrices for which, beyond the technological problem due to the high temperature in production, it is preferred to use fibers with better performance, for example carbon fibers, in relation to the high production cost.

In the civil engineering field, glass fibers are used in the manufacture of fiber cement products. The production methods for glass fibers are:

- In disused marble, it consisted in passing the spindle through drawing nozzles; 
- Disused wire rod drawing consisted of pulling glass rods to form fibers;

- With direct melting, the melt, slightly cooled but still plastic, is passed through platinum-iridium alloys (Pt-Ir) matrix, the fibers are coated with polymers to prevent them from melting together and arranged in bundles.

After spinning, the fiber is dressed to improve adhesion with the matrix to be reinforced (Table 1) [10].

Table 1. Glass fibers properties [10].

\begin{tabular}{c}
\hline Typical Properties of Glass Fibers \\
\hline Density: $2.48 \mathrm{~g} / \mathrm{cm}^{3}$ \\
\hline Elastic modulus: $90 \mathrm{GPa}$ \\
\hline Mechanical tensile strength (and new fiber): $4500 \mathrm{MPa}$ \\
\hline Percentage elongation at break: $5 \%$ \\
\hline
\end{tabular}

\subsection{Carbon Fiber}

As far as carbon fibers are concerned, these have properties similar to asbestos, but unlike the latter, their use does not entail health risks. Each weave of carbon filaments constitutes a whole formed by the union of many thousands of filaments. Each single filament has an approximately cylindrical shape with a diameter of 5-8 $\mu \mathrm{m}$ and consists almost exclusively of carbon (at least $92 \%$ ). The atomic structure of the carbon fiber is similar to that of graphite, consisting of aggregates of planar-structure carbon atoms (graphene sheets) arranged according to regular hexagonal symmetry. The difference lies in the way these sheets are interconnected. Graphite is a crystalline material in which the sheets are arranged parallel to each other forming a regular structure. The chemical bonds that are established between the sheets are relatively weak, giving the graphite its characteristic delicacy and fragility. Carbon fibers have a high chemical inertness towards many aqueous solutions. They will deteriorate if they come into contact with metals and metal oxides at temperatures above $1000 \mathrm{~K}$. The typical density of carbon fiber is $1750 \mathrm{~kg} / \mathrm{m}^{3}$. The mechanical strength of the different types of yarn varies between 2-7 GPa (Table 2) [16-20].

Table 2. Carbon Fiber commercial classification.

\begin{tabular}{|c|}
\hline $\begin{array}{l}\text { - GP (General Performance): characterized by lower mechanical resistance; they have } \\
\text { a Young's modulus not exceeding } 200 \mathrm{GPa} \text {; }\end{array}$ \\
\hline - LM (Low Modulus): they have low values of the Young's modulus; \\
\hline - HP (High Performance): characterized by greater mechanical strength \\
\hline $\begin{array}{l}\text { - HT (High Tensile Strength): they have high values of tensile strength (greater than } 3000 \mathrm{MPa} \text { [1]) } \\
\text { and standard values of Young's modulus (around 150-300 GPa [8]) }\end{array}$ \\
\hline - IM (Intermediate Modulus): have moderate values of Young's modulus (around 275-350 GPa [9]) \\
\hline - HM (High Modulus): they have high values of Young's modulus (greater than $300 \mathrm{GPa}$ ) \\
\hline - UHM (UltraHigh Modulus): they have high values of Young's modulus (greater than $600 \mathrm{GPa}$ ). \\
\hline
\end{tabular}

From the point of view of the process from which they are obtained, carbon fibers are further classified into:

- Carbon fibers from polyacrylonitrile (PAN): obtained through stabilization, carbonization and possible heat treatment at high temperature of the polyacrylonitrile; $90 \%$ of carbon fibers are currently produced according to this methodology;

- Carbon fibers from isotropic pitch: obtained from pitch fibers subjected to stabilization and carbonization; 
- Carbon fibers from anisotropic pitch (MPP, mesophase pitch): obtained from mesogenic pitch converted into mesophasic pitch during spinning; this mesophasic pitch is then subjected to stabilization, carbonization and high temperature heat treatment;

- Rayon carbon fibers: obtained from rayon fibers subjected to chemical pre-treatment and carbonization; this type of carbon fibers is no longer industrially produced;

- Gas phase carbon fibers: obtained from a gaseous phase containing hydrocarbons and solid catalysts; these carbon fibers are not currently marketed. Depending on the raw material used to produce the fiber, the carbon fiber could be turbostratic or graphitic, or possess a hybrid structure in which there are both turbostratic and graphitic parts. In the turbostratic carbon fiber, or with a crystalline structure formed by planes each deviated laterally with respect to the other, the sheets of carbon atoms are randomly joined or folded together. The carbon fibers obtained from the PAN are turbostratic, while the carbon fibers derived from the mesophase pitch are graphitic after heating at temperatures above $2200^{\circ} \mathrm{C}$. The turbostratic carbon fibers tend to have a greater tensile strength, while the mesophase-derived fibers subjected to heat treatment have high stiffness (Young's modulus) and high thermal conductivity [21-26].

The most commonly used method for obtaining carbon filaments is the oxidation and pyrolysis of polyacrylonitrile (PAN), a polymer obtained from the polymerization of acrylonitrile. The PAN is heated to approximately $300{ }^{\circ} \mathrm{C}$ in the presence of air, with the result of obtaining the oxidation and rupture of many hydrogen bonds established between the long polymeric chains. The oxidation product is placed in a furnace and heated to about $2000{ }^{\circ} \mathrm{C}$ in an inert gas atmosphere (for example argon), thus obtaining a radical change in the molecular structure with formation of graphite. By carrying out the heating process at the appropriate conditions, there is the condensation of the polymeric chains with the production of narrow sheets of graphene which merge and generate a single filament. The final result consists in obtaining a material with a carbon content generally ranging between $93 \%-95 \%$ [25].

The mechanical properties of carbon fiber could be further improved by exploiting appropriate heat treatments. Heating in the range of $1500-2000{ }^{\circ} \mathrm{C}$ results in the so-called carbonization with the formation of a material with a high tensile strength $(5650 \mathrm{MPa})$, while the carbon fiber subjected to graphitization (i.e., to a heating at $2500-3000{ }^{\circ} \mathrm{C}$ ) shows a higher modulus of elasticity (531 GPa). Carbon fiber is mainly used to reinforce composite materials, in particular those with a polymeric matrix. The materials thus obtained have high strength, lightness, low cost, and a certain aesthetic value. For these reasons, carbon fiber materials are widely used in a multiplicity of areas where the weight and mechanical resistance of the object are decisive factors or in consumer products simply for aesthetic purposes [26].

The lightness of these materials is also exploited in the sports field, where the lower weight of the sports equipment allows to increase the resistance of the athletes; in particular, these materials are used in the construction of:

- Racing car

- Bicycles

- Canoes

- Water skiing

- Soles of some soccer shoes

- Golf clubs

- Fishing rods

- Tennis rackets

- Archery

- Protective helmets

- Bodywork and components for rc cars

- Aircraft coverings

- Professional swimming costumes 
Another area where the lightness and low cost of carbon fiber materials are exploited is the music industry [10].

Carbon fibers could also be associated with matrices in non-polymeric material. Due to the formation of carbides (for example, water-soluble aluminum carbide) and problems related to corrosion phenomena, the use of carbon in metal matrix composites is underdeveloped. Carbon-carbon (RCC, reinforced carbon-carbon) consists of a reinforcement of carbon fiber in a graphite matrix and is used in applications that require exposure to high temperatures, such as in the case of heat shields for spacecraft or brakes of Formula 1 cars. This material is also used for high temperature gas filtration, as a high surface area corrosion resistant electrode, and as an antistatic component.

Carbon fiber is increasingly used to manufacture medical equipment due to both its transparency to X-rays and its robustness. Carbon fiber could be found on:

- Tables for supporting and positioning patients in radiological rooms

- Mobility aids such as crutches [20] orthopedic or Canadian, sticks, walkers, or wheelchairs

- Orthopedic equipment such as orthoses, prostheses or exoskeletons, prosthetic heart valves (Figures 2 and 3) (Table 3) [27,28].

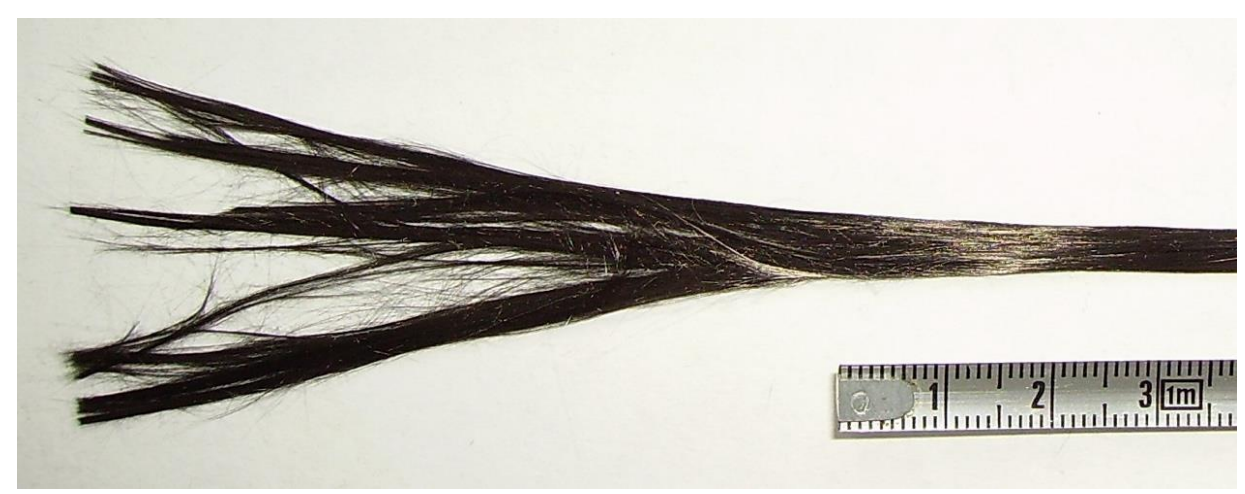

Figure 2. Carbon fiber filaments. Public Domain image.

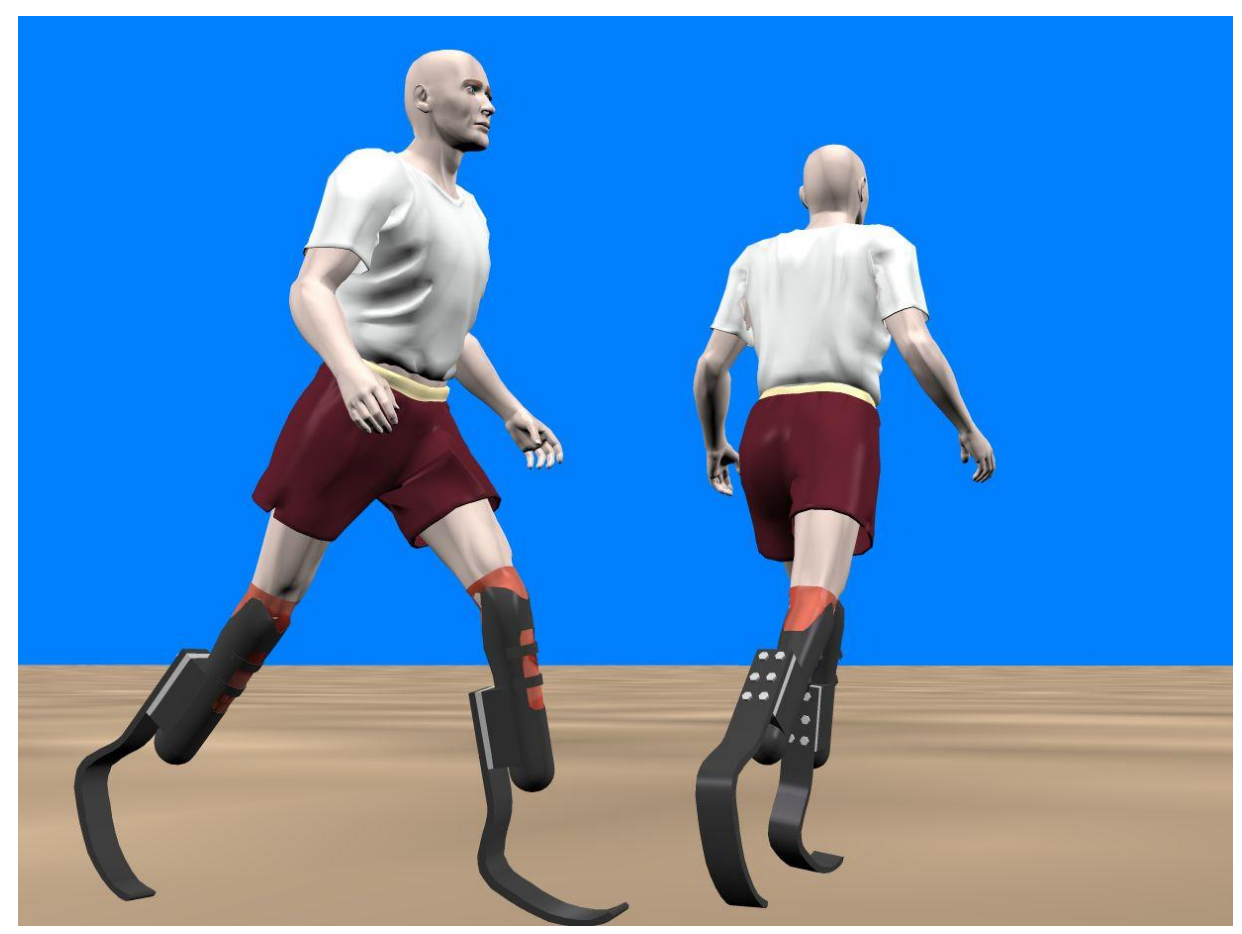

Figure 3. "Flex-Foot Cheetah" carbon prosthetic foot. By Anthony Appleyard CC BY SA 3.0. 
Table 3. Carbon vs. glass fibers mechanical features $[10,25]$.

\begin{tabular}{lcl}
\hline & Glass Fibers & Carbon Fibers \\
\hline Mechanical tensile strength $(\mathrm{Pa})$ & 1500 to $4500 \mathrm{MPa}$ & 150 to $600 \mathrm{GPa}$ \\
\hline
\end{tabular}

\section{Discussion}

The composite fibers therefore appear to give excellent biomechanical results and their biomechanical characteristics offer performance useful for use also as an endoprosthesis. An important aspect is represented by the fact that these materials, even before they are made with printing or milling systems, could be appropriately designed in such a way that their design respects the necessary biomechanical properties. [27-29]. These simulations could be performed by discretizing a real system and performing a finite element simulation [30-32]. Glass fiber finds its primary application as a reinforcement for long-term temporary crowns, for the temporary Toronto Bridge or the Maryland bridge, and for bridges on inlays. It could be used for bridges or inlays coated with dental composite for aesthetic purposes. Its advantages are: high resistance and elasticity; biocompatibility; adhesion to composites and resins; and optimal translucency. Among the various materials used in the dental field, carbon fiber is certainly one of the most innovative and stand outs from other polymers due to its great capacity to absorb loads, offering maximum patient comfort. It is no coincidence that this material is used in the manufacture of dental prostheses that require exceptional mechanical performance, such as the Toronto Bridge or crowns on implants. In this case the carbon fiber is used as a reinforcement support and generally in most restorative methods. All this was possible also thanks to the development and improvement of adhesive techniques, which allowed an ever increasing use of polymers in the dental field. Other materials already known, such as titanium, are able to be used in contact with tissues and to build prostheses [33,34], but composite materials, as already mentioned, are able to combine the mechanical characteristics of their components [35-41]; thus, obtaining hybrid materials with unique characteristics.

\section{Materials and Methods}

The literature search for this Communication was carried out on the most common Scopus, Pubmed, Embase, Clarivate Analytics scientific databases. The aim was to obtain the highest possible number of results on composite materials concerning the prosthetic field. Furthermore, it was to include only innovative materials and technological and prosthetic innovations.

Author Contributions: Conceptualization, L.F.; methodology, L.F.; investigation, L.F.; data curation, L.F. and G.A.; writing — review and editing, L.F.; writing — original draft, C.D.; investigation, A.Y.T.; visualization F.N.; supervision and project administration, G.R. All authors have read and agreed to the published version of the manuscript.

Funding: This research received no external funding.

Conflicts of Interest: The authors declare no conflict of interest.

\section{References}

1. Cicciù, M. Prosthesis: New Technological Opportunities and Innovative Biomedical Devices. Prosthesis 2019, 1, 1-2. [CrossRef]

2. Katoh, Y.; Kohyama, A.; Nozawa, T.; Sato, M. SiC/SiC composites through transient eutectic-phase route for fusion applications. J. Nucl. Mater. 2004, 329-333, 587-591. [CrossRef]

3. Pizzicannella, J.; Diomede, F.; Gugliandolo, A.; Chiricosta, L.; Bramanti, P.; Merciaro, I.; Orsini, T.; Mazzon, E.; Trubiani, O. 3D Printing PLA/Gingival Stem Cells/EVs Upregulate miR-2861 and -210 during Osteoangiogenesis Commitment. Int. J. Mol. Sci. 2019, 20, 3256. [CrossRef] [PubMed]

4. Jacobs, A.; Gaulier, M.; Duval, A.; Renaudin, G. Silver Doping Mechanism in Bioceramics-From Ag+: Doped HAp to $\mathrm{Ag}^{\circ} / \mathrm{BCP}$ Nanocomposite. Crystals 2019, 9, 326. [CrossRef] 
5. Ferracini, R.; Bistolfi, A.; Garibaldi, R.; Furfaro, V.; Battista, A.; Perale, G. Composite Xenohybrid Bovine Bone-Derived Scaffold as Bone Substitute for the Treatment of Tibial Plateau Fractures. Appl. Sci. 2019, 9, 2675. [CrossRef]

6. Chen, S.; Auriat, A.M.; Li, T.; Stumpf, T.R.; Wylie, R.; Chen, X.; Willerth, S.M.; DeRosa, M.; Tarizian, M.; Cao, X.; et al. Advancements in Canadian Biomaterials Research in Neurotraumatic Diagnosis and Therapies. Processes 2019, 7, 336. [CrossRef]

7. Ali, S.; Abdul Rani, A.M.; Mufti, R.A.; Hastuty, S.; Hussain, M.; Shehzad, N.; Baig, Z.; Abdu Aliyu, A.A. An Efficient Approach for Nitrogen Diffusion and Surface Nitriding of Boron-Titanium Modified Stainless Steel Alloy for Biomedical Applications. Metals 2019, 9, 755. [CrossRef]

8. Paryag, A.; Lowe, J.; Rafeek, R. Colored Gingiva Composite Used for the Rehabilitation of Gingiva Recessions and Non-Carious Cervical Lesions. Dent. J. 2017, 5, 33. [CrossRef]

9. Chinelatti, M.A.; Santos, E.L.; Tirapelli, C.; Pires-de-Souza, F.C.P. Effect of Methods of Biosilicate Microparticle Application on Dentin Adhesion. Dent. J. 2019, 7, 35. [CrossRef]

10. Corigliano, P.; Crupi, V.; Epasto, G.; Guglielmino, E.; Risitano, G. Fatigue Assessment by Thermal Analysis during Tensile Tests on Steel. Procedia Eng. 2015, 109, 210-218. [CrossRef]

11. Cucinotta, F.; Guglielmino, E.; Risitano, G.; Sfravara, F. Assessment of Damage Evolution in Sandwich Composite Material Subjected to Repeated Impacts by Means Optical Measurements. Procedia Struct. Integr. 2016, 2, 3660-3667. [CrossRef]

12. Giudice, G.; Cicciù, M.; Cervino, G.; Lizio, A.; Visco, A. Flowable resin and marginal gap on tooth third medial cavity involving enamel and radicular cementum: A SEM evaluation of two restoration techniques. Indian J. Dent. Res. 2012, 23, 763-769. [PubMed]

13. Taheri, H.; Hassen, A.A. Nondestructive Ultrasonic Inspection of Composite Materials: A Comparative Advantage of Phased Array Ultrasonic. Appl. Sci. 2019, 9, 1628. [CrossRef]

14. Spelter, A.; Bergmann, S.; Bielak, J.; Hegger, J. Long-Term Durability of Carbon-Reinforced Concrete: An Overview and Experimental Investigations. Appl. Sci. 2019, 9, 1651. [CrossRef]

15. Gao, K.; Li, Z.; Zhang, J.; Tu, J.; Li, X. Experimental Research on Bond Behavior between GFRP Bars and Stirrups-Confined Concrete. Appl. Sci. 2019, 9, 1340. [CrossRef]

16. Zhou, W.; Zhang, P.-f.; Zhang, Y.-n. Acoustic Emission Based on Cluster and Sentry Function to Monitor Tensile Progressive Damage of Carbon Fiber Woven Composites. Appl. Sci. 2018, 8, 2265. [CrossRef]

17. Zhao, Q.; Zhang, K.; Zhu, S.; Xu, H.; Cao, D.; Zhao, L.; Zhang, R.; Yin, W. Review on the Electrical Resistance/Conductivity of Carbon Fiber Reinforced Polymer. Appl. Sci. 2019, 9, 2390. [CrossRef]

18. Otani, T.; Hashimoto, K.; Miyamae, S.; Ueta, H.; Natsuhara, A.; Sakaguchi, M.; Kawakami, Y.; Lim, H.-O.; Takanishi, A. Upper-Body Control and Mechanism of Humanoids to Compensate for Angular Momentum in the Yaw Direction Based on Human Running. Appl. Sci. 2018, 8, 44. [CrossRef]

19. Kim, R.-W.; Kim, C.-M.; Hwang, K.-H.; Kim, S.-R. Embedded Based Real-Time Monitoring in the High-Pressure Resin Transfer Molding Process for CFRP. Appl. Sci. 2019, 9, 1795. [CrossRef]

20. Ayyagari, S.; Al-Haik, M. Enhancing the Viscoelastic Performance of Carbon Fiber Composites by Incorporating CNTs and ZnO Nanofillers. Appl. Sci. 2019, 9, 2281. [CrossRef]

21. Vercio, R.C.; Basmajian, H.G. Fracture of a Carbon Fiber Reinforced Intramedullary Femoral Nail. J. Am. Acad. Orthop. Surg. 2019, 27, e585-e588. [CrossRef] [PubMed]

22. Pesce, P.; Lagazzo, A.; Barberis, F.; Repetto, L.; Pera, F.; Baldi, D.; Menini, M. Mechanical characterisation of multi vs. uni-directional carbon fiber frameworks for dental implant applications. Mater. Sci. Eng. C Mater. Biol. Appl. 2019, 102, 186-191. [CrossRef] [PubMed]

23. Mehl, B.T.; Martin, R.S. Integrating 3D Cell Culture of PC12 Cells with Microchip-Based Electrochemical Detection. Anal. Methods Adv. Methods Appl. 2019, 11, 1064-1072. [CrossRef] [PubMed]

24. Liu, H.; Zhang, S.; Yang, J.; Ji, M.; Yu, J.; Wang, M.; Chai, X.; Yang, B.; Zhu, C.; Xu, J. Preparation, Stabilization and Carbonization of a Novel Polyacrylonitrile-Based Carbon Fiber Precursor. Polymers 2019, 11, 1150. [CrossRef]

25. Gao, Y.; Duan, X.; Jiang, P.; Zhang, H.; Liu, J.; Wen, S.; Zhao, X.; Zhang, L. Molecular dynamics simulation of the electrical conductive network formation of polymer nanocomposites by utilizing diblock copolymer-mediated nanoparticles. Soft Matter 2019, 15. [CrossRef]

26. Erdenechimeg, K.; Jeong, H.I.; Lee, C.M. A Study on the Laser-Assisted Machining of Carbon Fiber Reinforced Silicon Carbide. Materials 2019, 12, 2061. [CrossRef] 
27. Risitano, A.; Clienti, C.; Risitano, G. Determination of fatigue limit by mono-axial tensile specimens using thermal analysis. Key Eng. Mater. 2009, 452, 361-364. [CrossRef]

28. Fargione, G.; Tringale, D.; Guglielmino, E.; Risitano, G. Fatigue characterization of mechanical components in service. Frattura ed Integrita Strutturale 2013, 26, 143-155. [CrossRef]

29. Cicciù, M.; Cervino, G.; Milone, D.; Risitano, G. FEM investigation of the stress distribution over mandibular bone due to screwed overdenture positioned on dental implants. Materials 2018, 11, 1512. [CrossRef]

30. Bramanti, E.; Cervino, G.; Lauritano, F.; Fiorillo, L.; D'Amico, C.; Sambataro, S.; Denaro, D.; Fama, F.; Ierardo, G.; Polimeni, A.; et al. FEM and Von Mises Analysis on Prosthetic Crowns Structural Elements: Evaluation of Different Applied Materials. Sci. World J. 2017, 2017, 1029574. [CrossRef]

31. Cervino, G.; Romeo, U.; Lauritano, F.; Bramanti, E.; Fiorillo, L.; D'Amico, C.; Milone, D.; Laino, L.; Campolongo, F.; Rapisarda, S.; et al. Fem and Von Mises Analysis of OSSTEM (r) Dental Implant Structural Components: Evaluation of Different Direction Dynamic Loads. Open Dent. J. 2018, 12, 219-229. [CrossRef] [PubMed]

32. Portelli, M.; Militi, A.; Logiudice, A.; Nucera, R. An Integrated Approach, Orthodontic and Prosthetic, in a Case of Maxillary Lateral Incisors Agenesis. Prosthesis 2020, 1, 3-10. [CrossRef]

33. McGrory, A.; McGrory, B.; Rana, A.; Babikian, G. Incidence of Heterotopic Ossification in Anterior Based Muscle Sparing Total Hip Arthroplasty: A Retrospective Radiographic Review. Prosthesis 2020, 1, 11-15. [CrossRef]

34. Frossard, L.; Jones, M.; Stewart, I.; Leggat, P.; Schuetz, M.; Langton, C. Kinetics of Lower Limb Prosthesis: Automated Detection of Vertical Loading Rate. Prosthesis 2020, 1, 16-28. [CrossRef]

35. Ortensi, L.; Vitali, T.; Bonfiglioli, R.; Grande, F. New Tricks in the Preparation Design for Prosthetic Ceramic Laminate Veeners. Prosthesis 2020, 1, 29-40. [CrossRef]

36. Cicciù, M.; Cervino, G.; Terranova, A.; Risitano, G.; Raffaele, M.; Cucinotta, F.; Santonocito, D.; Fiorillo, L. Prosthetic and Mechanical Parameters of the Facial Bone under the Load of Different Dental Implant Shapes: A Parametric Study. Prosthesis 2020, 1, 41-53. [CrossRef]

37. Cervino, G.; Montanari, M.; Santonocito, D.; Nicita, F.; Baldari, R.; De Angelis, C.; Storni, G.; Fiorillo, L. Comparison of Two Low-Profile Prosthetic Retention System Interfaces: Preliminary Data of an In Vitro Study. Prosthesis 2020, 1, 54-60. [CrossRef]

38. Iovino, P.; Di Sarno, A.; De Caro, V.; Mazzei, C.; Santonicola, A.; Bruno, V. Screwdriver Aspiration During Oral Procedures: A Lesson for Dentists and Gastroenterologists. Prosthesis 2020, 1, 61-68. [CrossRef]

39. Sambataro, S.; Cervino, G.; Fiorillo, L.; Cicciu, M. Upper First Premolar Positioning Evaluation for the Stability of the Dental Occlusion: Anatomical Considerations. J. Craniofac. Surg. 2018, 29, 1366-1369. [CrossRef]

40. Cicciu, M.; Fiorillo, L.; Herford, A.S.; Crimi, S.; Bianchi, A.; D’Amico, C.; Laino, L.; Cervino, G. Bioactive Titanium Surfaces: Interactions of Eukaryotic and Prokaryotic Cells of Nano Devices Applied to Dental Practice. Biomedicines 2019, 7, 12. [CrossRef]

41. Cervino, G.; Fiorillo, L.; Iannello, G.; Santonocito, D.; Risitano, G.; Cicciù, M. Sandblasted and Acid Etched Titanium Dental Implant Surfaces Systematic Review and Confocal Microscopy Evaluation. Materials 2019, 12, 1763. [CrossRef] [PubMed]

(C) 2020 by the authors. Licensee MDPI, Basel, Switzerland. This article is an open access article distributed under the terms and conditions of the Creative Commons Attribution (CC BY) license (http://creativecommons.org/licenses/by/4.0/). 